\title{
A POESIA COMO RECURSO DE DESENVOLVIMENTO DO UNIVERSO CULTURAL E CRIATIVO DA CRIANÇA ${ }^{1}$
}

\author{
SILVA, Ana Cláudia Mendes da² \\ COSTA, Sueli Silva Gorricho ${ }^{3}$
}

\begin{abstract}
RESUMO: A presente pesquisa focaliza o movimento intertextual que acontece na sala de aula com a leitura de poesias para crianças. Para a abordagem deste trabalho, que aconteceu em uma $4^{\mathrm{a}}$ série do Ensino Fundamental, de uma escola pública, foram utilizados livros, textos, entrevista e poesias. Observou-se cada etapa e percebeu-se a necessidade de escolher textos que agradem às crianças e desperte-as para outras leituras.
\end{abstract}

Palavras-chave: Poesia. Literatura infantil. Leitura. Aprendizagem. Educação.

\begin{abstract}
The present paper focuses on the intertextual movement that happens in the classroom with reading of poetries for children. For the comprehension this work, that toke place in a 4th series of Fundamental Education, of a public school, books, texts, interview and poetries were used. Each stage was observed and it was noticed the need to choose texts that please the children and wake up them for other readings.
\end{abstract}

Keywords: Poetry. Childish literature. Reading. Learning. Education.

\section{INTRODUÇÃO}

Desde tempos remotos a Literatura esteve presente nas civilizações para contar histórias, narrar o passado e fixar a memória do homem. O trabalho com a literatura na sala de aula pode levar os alunos a partilharem seus conhecimentos, e Smolka (1988), diz que isso acontece:

Porque a literatura, como discurso escrito, revela, registra e trabalha formas e normas do discurso social; ao mesmo tempo, instaura e amplia o espaço interdiscursivo, na medida em que inclui outros interlocutores - de outros lugares, de outros tempos -, criando novas condições e novas possibilidades de troca de saberes, convocando os ouvintes/ leitores a participarem como protagonistas no diálogo que se estabelece.

Assim, ao ter a poesia como objeto deste estudo, procura-se estabelecer um elo entre as implicações teóricas e a prática na perspectiva histórico-cultural de Vygotsky.

O objetivo deste estudo é verificar o processo de desenvolvimento da compreensão com a leitura de poesias, tendo por base o trabalho com os alunos de uma $4^{\text {a }}$ série do Ensino fundamental, que apesar de já possuírem conhecimento sobre leitura, têm pouco contato com textos poéticos.

1 Este artigo faz parte do Trabalho de Conclusão de Curso (TCC), da autora.

2 Graduanda em Pedagogia. Licenciatura Plena.

3 Prof. ${ }^{\text {a }}$ MSc. dos cursos de Letras e Pedagogia da Faculdade de Filosofia Ciências e Letras de Ituverava, orientadora do Trabalho. 
Segundo André (1991),

O estudo do cotidiano escolar se coloca como fundamental para se compreender como a escola desempenha o seu papel socializador, seja na transmissão dos conteúdos acadêmicos, seja na veiculação das crenças e valores que aparecem nas ações, interações, nas rotinas e nas relações sociais que caracterizam o cotidiano da experiência escolar.

Na primeira parte, apresentam-se alguns conceitos sobre literatura, literatura infantil, poesia e poesia infantil.

Na segunda parte, são mostradas as implicações pedagógicas do modelo históricocultural de Vygotsky, que serão norteadores das reflexões propostas no estudo.

Já na terceira parte, busca-se compreender a importância da leitura literária na escola.

E na quarta parte, analisa-se o desenvolvimento e a compreensão das atividades empíricas realizadas na pesquisa.

Este trabalho foi desenvolvido em sala de aula e mostrou a importância do envolvimento dos alunos com a poesia, e o papel de mediação consciente do professor em uma relação de ensino-aprendizagem.

Vygotsky (2001)

Considera o mestre, do ponto de vista psicológico, o organizador do meio social educativo, o regulador e controlador da sua interação com o educando (...). O meio social é a verdadeira alavanca do processo educacional, e todo o papel do mestre consiste em direcionar essa alavanca.

Interessante seria ampliar a capacidade de leitura e entendimento, estimular os alunos a pensarem sobre o sentido das palavras no texto poético. Desse modo, os alunos compreenderiam os vários significados/ sentidos que pode ter uma palavra, em um texto poético. Assim, ficaria mais fácil para eles se tornarem leitores críticos, sem perderem o prazer pela leitura.

\section{METODOLOGIA}

Este estudo se realiza por meio da leitura e compreensão de poesias, na sala de aula, desenvolvido durante o período do estágio, com participações e observações realizadas na escola.

Foram usadas várias poesias deautores diversos, realizadas leituras edepoisacompreensão, que se deu através do desenho (ilustração individual), em um primeiro momento.

Os procedimentos metodológicos utilizados foram: a interpretação dos referenciais bibliográficos, aplicação de uma entrevista, clara e objetiva, aos alunos, indagando sobre a freqüência com que lêem poesias e análise de atividades propostas com as poesias como: desenhos, entendimento verbal e produção de poesias.

Para a realização da pesquisa considera-se a análise dos dados obtidos através do registro 
da observação, que adveio das anotações da pesquisadora; das ilustrações e da compreensão dos alunos, em exercícios realizados na sala de aula.

Ao final do trabalho, considerou-se a análise dos dados e pretendeu-se sugerir, bem como chamar a atenção para a importância da leitura de poesias na sala de aula.

A classificação dos resultados obtidos considerou a análise de cada atividade, de cada dado registrado e da observação.

Durante o trabalho, o caminho teórico-metodológico a ser seguido, teve como norteadoras as considerações de Vygotsky.

\section{LITERATURA E POESIA}

\subsection{LITERATURA}

Segundo Luft (1996), a palavra literatura quer dizer: "Arte de produzir obras literárias. Conjunto de normas a que obedece a estruturação das obras de arte verbal. Conjunto de obras ou de escritos literários".

Pelo minidicionário Rocha (1996), literatura é a "arte que emprega como instrumento a palavra. Conjunto de produções dessa arte. Conjunto de obras sobre uma arte ou ciência".

De acordo com Ferreira (1995), literatura significa:

Do lat. Litteratura, Substantivo feminino. 1. Arte de compor ou escrever trabalhos artísticos em prosa ou verso. 2. O conjunto de trabalhos literários dum país ou duma época. 3. Os homens de letras: A literatura brasileira fez-se representar no colóquio de Lisboa.

Candido (1973) define a arte e a literatura como a passagem do "real para o ilusório por meio de uma estilização formal". Isso põe em destaque o caráter imaginário e irreal de literatura, bem como o seu princípio estético, e tem a liberdade de mostrar o mundo de forma criativa e autônoma.

Assim, a literatura proporciona ao homem conhecimento sobre os seres e o mundo, forma a sua personalidade e satisfaz as suas necessidades quanto à fantasia e à imaginação. Amplia o conhecimento de mundo e o crescimento interior.

Por essa razão a literatura não pode ser usada na escola como ensinamento moral e orientação sobre valores, pois assim ela corre o risco de ser vista apenas como pedagogia. Essa preocupação deve-se estender também à literatura infanto-juvenil.

Quando se fala em literatura adulta, juvenil ou infantil, deve-se pensar primeiro que ela é arte, que possui características próprias e dirigi-se a um público específico. Essa literatura implica em liberdade de criação para o autor e em liberdade de interpretação para o leitor, e isso só se configura na obra através de sua função estética.

Nucleus, v. 5. n. 1 , abr. 2008 
A partir dos anos 70, houve uma produção muito grande de obras infantil $1^{4}$ e juvenil, o que contribuiu para inverter uma concepção utilitarista da literatura e mostrar o mundo às crianças de maneira mais crítica e ao mesmo tempo lúdica. Seja pelo protesto, pelo suspense, pela modernidade, pelo discurso metalingüístico e intertextual, seja pela poesia anticonvencional.

Quanto aos temas, busca o caminho do realismo crítico, da subjetividade e da fantasia. Assim, o gênero infanto-juvenil marca a partir dos anos 70 um novo momento estético e ideológico que vai desabrochar pelos anos 80 e 90. Esse período de mudança de concepção, que o escritor passa a ter da infância e da juventude, resulta em uma grande conquista artística para o gênero, seja pela temática e/ou pela forma de expressão, em prosa ou em verso.

Vários autores têm contribuído para o crescimento desse universo literário infantojuvenil. Ana Maria Machado, Ligia Bojunga Nunes, Ziraldo, Marina Colassanti, Vivinha de Assis Viana, Ruth Rocha, Juarez Machado, Ciça e Zélio, Sidônio Muralha, Cecília Meireles, Mário Quintana, Vinícius de Moraes, e muitos outros; ao criarem obras que romperam com o ensinamento moral e priorizaram o lúdico, o prazeroso, a liberdade de expressão, as verdades e denúncias da realidade social e familiar.

\subsubsection{LITERATURA INFANTIL}

Existe uma grande discussão entre os teóricos, pedagogos para se entender e chegar a definições do que vem a ser a Literatura Infantil. Discute-se no nível de conceituação, da concepção do que é infância e do leitor, a ligação entre a literatura infantil e a escola, até o caráter literário que essas obras têm para crianças.

A origem da Literatura Infantil tem suas origens na Índia, na Novelística Popular Medieval, através da tradição oral.

Em relação aos primeiros livros voltados para crianças esses surgem somente no final do século XVII, escritos por professores e pedagogos. E estes estavam diretamente relacionados a uma função utilitário-pedagógica, ou seja, serviam como material complementar dentro da escola, por isso, foram sempre considerados uma forma literária menor. A produção desses livros voltados para a infância surgiu com o objetivo de ensinar valores (caráter didático), ajudar a enfrentar a realidade social e propiciar a adoção de hábitos ali explicitados. Atualmente, ainda podem-se encontrar esses objetivos explícitos na produção infantil contemporânea.

Para se entender melhor essa função utilitário-pedagógica que se encontra presente na literatura infanto-juvenil, apresenta-se alguns conceitos literários na visão e concepção de diferentes autores e épocas.

Segundo Palo e Oliveira (1986),

Dentro do contexto da literatura infantil, a função pedagógica implica a ação educativa do livro sobre a criança. De um lado, relação comunicativa leitor-obra, tendo por intermediário o pedagógico, que dirige e orienta o uso da informação; de outro, a cadeia de mediadores que interceptam a relação livro-criança: família,

$4 \quad$ Será enfoque de interesse doravante desse trabalho. 
escola, biblioteca e o próprio mercado editorial, agentes controladores de usos que dificultam à criança a decisão e escolha do que e como ler. Extremamente pragmática essa função pedagógica tem em vista uma interferência sobre o universo do usuário através do livro infantil, da ação de sua linguagem, servindo-se da força material que palavras e imagens possuem como signos que são, de atuar sobre a mente daquele que as usa; no caso, a criança.

Para alguns é necessário que se veja o objeto a partir de vários pontos de vista o que ajuda a entender e assim a elaborar o conceito do que vem a ser literatura infantil. A literatura infantil também já foi abordada como uma questão de estilo para alguns.

Para Coelho (2000),

A literatura, e em especial a infantil, tem uma tarefa fundamental a cumprir nesta sociedade em transformação: a de servir como agente de formação, seja no espontâneo convívio leitor/ livro, seja no diálogo leitor/ texto, estimulado pela escola.

Por outro lado, já na década de 40, Andrade (1964), questionou se a literatura infantil é destinada a crianças ou será uma literatura que interessa a crianças? Esta é uma questão que até hoje permanece sem resposta diante de tantas divergências. Assim, o autor expressou seu pensamento:

O gênero "literatura infantil" tem, a meu ver, a existência duvidosa. Haverá música infantil? Pintura infantil? A partir de que ponto uma obra literária deixa de se constituir alimento para o espírito da criança ou jovem e se dirige ao espírito adulto? Qual o bom livro para crianças, que não seja lido com interesse pelo homem feito? Qual o livro de viagens ou aventuras, destinado a adultos, que não possa ser dado a crianças, desde que vazado em linguagem simples e isento de matéria de escândalo?

Dessa forma, muito se discute o que vem a ser a literatura infantil. Com o questionamento de Drummond - "Será a criança um ser a parte, reclamando uma literatura também à parte?", nos perguntamos? Será que existe uma literatura produzida para crianças e jovens? O que poderia significar então uma literatura voltada para a clientela escolar e assim, produzida para consumo dentro da escola e dessa forma ajudar no processo de escolarização.

Percebe-se então que a literatura infantil no Brasil acompanha o ritmo do desenvolvimento marcado pela educação. A explosão de literaturas infantis está associada aos governos que incentivam a leitura nas séries iniciais e que coincidentemente ocorrem ao mesmo tempo em que se anunciam mais vagas nas escolas públicas. Assim, a literatura infantil pode estar diretamente ligada à escolarização, uma vez que ela se torna produzida para a escola.

\subsection{POESIA}

O que é a poesia? Não há definição objetiva dela, mas a poesia é, talvez, a expressão de sentimentos, emoções e sentidos do poeta em relação àquilo que o rodeia ou pelo que toma como tema, revelada numa forma escrita, cuja sonoridade e estrutura, muitas vezes se assemelham a 
um cântico, a um apelo, etc.

Analisando-a no plano fônico, a poesia não é uma linguagem comum que serve somente para significar. Ela consegue criar um conjunto de sons agradáveis e melodiosos através da rima, do ritmo e de várias figuras de estilo como a repetição que é freqüentemente utilizada.

A poesia consegue tornar visível algo abstrato como os sentimentos, em realidades quase palpáveis. Uma das formas mais representativas da poesia é o lirismo que não é mais do que a expressão do "eu”, ou seja, a expressão de sentimentos.

Aí, o poeta fala do que sente; revela-nos o seu estado de espírito, de um modo que é estranho ao homem em geral, que muitas vezes é tomado pelos mesmos sentimentos e sensações, mas que não é capaz de revelá-los da mesma forma. Aliás, como o são os sentimentos, a poesia não é regida por um modelo generalizado: cada poeta tem a sua forma, o seu estilo, o seu método de escrever.

O poeta poderá também apresentar como tema aquilo que o rodeia. Interioriza o que lhe é externo e trata-o de uma forma sentida, expondo o resultado, de um modo geral, completamente transformado, à sua maneira: revela um mundo criado por si a partir de um mundo que lhe passa ao lado.

É uma arte; é um dom que só alguns possuem. É conseguir fazer chorar a partir de um motivo para rir. É tão somente viver poesia, ou experimentar o que se chama sentimento poético.

De acordo com Aurélio (1998),

Origina-se do gr. poíesis, 'ação de fazer algo', pelo lat. poese, + -ia. Substantivo feminino. 1. Arte de escrever em verso. 2. Composição poética de pequena extensão. 3. Entusiasmo criador; inspiração. 4. Aquilo que desperta o sentimento do belo. 5.0 que há de elevado ou comovente nas pessoas ou nas coisas. 6. Encanto, graça, atrativo. Poesia pura. 1. Arte Poét. Corrente da poesia moderna que renuncia à expressão de sentimentos individuais e ao material anedótico.

Em Luft (1996), poesia é substantivo feminino. "1. Arte de escrever em verso. 2. Composição poética pouca extensa. 3. Inspiração".

Ao buscar outras definições e conceitos para poesia, Lyra (1986), em seu ensaio diz:

A poesia, por sua vez, é situada de modo problemático em dois grandes grupos conceituais: ora como uma pura e complexa substância imaterial, anterior ao poeta e independente do poema e da linguagem, e que apenas se concretiza em palavras como conteúdo do poema, mediante a atividade humana; ora como a condição dessa indefinida e absorvente atividade humana, o estado em que o indivíduo se coloca na tentativa de captação, apreensão e resgate dessa substância no espaço abstrato das palavras.

Pode-se verificar, então, que a poesia vai além do saber escrever bem, ela é a arte de expressar sentimentos acerca dos elementos que rodeiam o poeta, e pode ser encontrada nas formas mais simples da vida.

O gênero poético tem uma configuração distinta dos demais gêneros literários. Sua 
brevidade, aliada ao potencial simbólico apresentado, transforma a poesia em uma atraente e lúdica forma de contato com o texto literário.

A poesia se caracteriza por três elementos associativos: subjetividade, estrutura em versos e ritmo.

A subjetividade que é uma visão particular do autor; a estrutura em versos que orienta a leitura e a interpretação do texto e o ritmo que o distingue de outro texto. Nesses versos a seguir percebe-se claramente a estrutura em versos e a repetição dos sons (ua, orta). (RICARDO, 1975), Serenata Sintética: Rua Torta/ Rua Morta/ Tua Porta

Quanto à linguagem as poesias apresentam palavras com novos e múltiplos significados, e também palavras com sonoridade.

Como se pode ver nesse poema de Cecília Meireles (MEIRELES, 1979):

\title{
Rola a chuva
}

Arre

Que arrelia!

O frio arrepia

A moça arredia.

Na rua rola a roda...

Arreda!

A rola arrulha na torre.

A chuva sussurra

Rola a chuva,

rega a terra,

rega o rio

rega a rua.

E na rua a roda rola.

O poeta às vezes coloca as palavras de tal forma que chega a sugerir uma imagem, como nesse poema de Manuel Bandeira em que ele tentou reproduzir o som e o movimento das ondas do mar. (BANDEIRA, 1986):

\author{
A onda \\ A onda anda \\ Aonde anda a onda? \\ A onda ainda \\ Ainda onda \\ Ainda anda a onde? \\ Aonde? \\ A onda a onda
}

\subsubsection{A POESIA INFANTIL}

Pensar em poesia infantil é antes de qualquer coisa, procurar emoção e harmonia em poemas diversificados que apresentem material poético fácil e difícil, longo e curto, com ou sem rima, que seja menos comprometido com aspectos morais e pedagógicos. Segundo Abramovich 
(1994), "tem quem ache que a poesia infantil tem que ser moralizadora, pequenina, tratar temas patrióticos, falar de assuntos piegas [...]. A Poesia para crianças, tem que ser antes de tudo muito boa! De primeiríssima qualidade!!! [...]”.

Ou como diz Paes (1996), em seu livro É isso ali:

\begin{abstract}
A poesia não é mais do que uma brincadeira, com as palavras. Nessa brincadeira cada palavra pode e deve significar mais de uma coisa ao mesmo tempo: isso aí é também isso ali. Toda poesia tem que ter uma surpresa. Se não tiver, não é poesia: é papo furado.
\end{abstract}

Existem poetas que quase brincam com as palavras, e assim cativam as crianças que ouvem, ou lêem esse tipo de texto. Lidam com toda uma ludicidade verbal, sonora e musical, no jeito como juntam as palavras fazendo trocadilhos e acaba por tornar a leitura algo muito divertido.

\title{
O menino dos FF e RR
}

O menino dos ff e rr É o Orfeu Orófilo Ferreira

Ai com tantos rr, não erres!

\section{(Cecília Meireles)}

Como recursos para despertar o interesse do pequeno leitor, os autores utilizam-se de rimas bem simples e que usem palavras do cotidiano infantil; um ritmo que apresente certa musicalidade ao texto; repetição, para fixação da idéias, e melhor compreensão dentre outros.

\section{As meninas}

Arabela

Abria a janela

Carolina

Erguia a cortina

E Maria

Olhava e sorria:

"Bom dia!"

Arabela

Foi sempre a mais bela

Carolina

A mais sábia menina

E Maria

Apenas sorria:

"Bom dia!"

Pensaremos em cada menina

Que vivia naquela janela;

Uma que se chamava Arabela,

Outra que se chamou Carolina!

Mas a nossa profunda saudade

É Maria, Maria, Maria

Que dizia com voz de amizade:

"Bom dia!"

(Cecília Meireles) 
Ao refletir acerca da receptividade das crianças à poesia, Sosa (1993), diz:

[...] a criança tem uma alma poética. E é essencialmente criadora. Assim, as palavras do poeta, as que procuraram chegar até ela pelos caminhos mais naturais, mesmo sendo os mais profundos em sua síntese, não importa, nunca serão melhor recebidas em lugar algum do que em sua alma, por ser mais nova, mais virgem [...]

Pode-se dizer que a poesia infantil é um gênero literário que sofre os maiores preconceitos editoriais, pois se edita muito pouco, e sem muito critério.

Grandes poetas brasileiros não têm versões infantis de suas obras e poetas menores que não dominam os versos, que não sabem falar de modo sensível e belo, têm suas pobres palavras impressas e consideradas poesias.

Os que acham que a poesia infantil tem que ser predominantemente moralizadora, falar sobre os costumes edificantes, do dia-a-dia, dos bons hábitos de higiene ou ainda glorificar o dia das mães ou o dia do índio, tratar de temas cívicos e colocar os alunos para recitá-la em datas comemorativas. Isso certamente, por serem tão restritas e diretas, já tem grandes chances de não serem boa poesia. E normalmente são mal escritas, e acabam por entediar as crianças em suas leituras.

Outros pensam que a poesia para crianças deva ser bem pequenininha, até mesmo bobinha, mimosinha e outros detalhes mais. Escrever no diminutivo pode irritar a criança, pois esse fato a associa a um bebê. Esquece-se que a criança está numa fase de descobrimentos e que os assuntos devem ser interessantes para ela.

No Brasil, um fato curioso é que poetas escreveram poucos livros de poemas para crianças: Cecília Meireles, Vinícius de Moraes, Henriqueta Lisboa, escreveram apenas um. Entre os escritores vivos, destaca-se a obra de Sérgio Caparelli, que tem uma produção para criança.

Para Pinheiro (2000),

[...] não se pode falar que há pouca publicação de livros de poemas destinados ao público infantil no Brasil. Nas décadas de 80 e 90, houve um aumento significativo de livros de poemas para criança. Tivemos acesso a mais de cinqüenta obras e constatamos que alguns poetas chegaram a publicar mais de cinco livros do gênero. Se o número parece significativo, a qualidade estética das obras é quase sempre passível de críticas. Dificilmente encontramos livros que alcancem o equilíbrio estético de $\mathrm{Ou}$ isto ou aquilo, de Cecília Meireles ou da Arca de Noé, de Vinícius de Moraes.

Na infância há um enorme prazer em ler poemas, em saborear versos, em brincar com as palavras, em satisfazer as necessidades lúdicas e sonoras das crianças.

Segundo Paes (1996),

[...] A poesia tende a chamar a atenção da criança para as surpresas que podem estar escondidas na língua que ela fala todos os dias sem se dar conta delas. Por exemplo, a rima, ou seja, a semelhança dos sons finais entre duas palavras sucessivas, obriga o 
leitor a voltar atrás na leitura. Esta passa então a ser feita não linha após linha, sempre para frente, como na prosa, e sim num ir e vir entre o que está adiante e o que ficou atrás. Com isso, desautomatiza-se a leitura e se direciona a atenção para o conjunto de significados do texto, não apenas para a seqüência deles.

Hoje, vários autores dão sugestões de como trabalhar com o texto poético na sala de aula e também sugerem como o professor deve selecionar o seu material. Mas o importante é o professor primeiro conhecer o poema, amar o poema, pois é impossível transmitir uma emoção, um gosto que não se sente. A poesia é para ser sentida e não entendida.

Para que a poesia chegue até as crianças, via escola, Pinheiro (2000), diz:

\begin{abstract}
Mais que receitas, precisamos desenvolver e assumir algumas posturas quanto à leitura do poema e a leitura em geral. Atrevo-me a sugerir algumas destas posturas ao professor que deseja, em diferentes situações, levar a poesia a seus alunos: 1) não se fixar, de modo absoluto, no que deu ou não certo em experiências anteriores; 2) não buscar resultados imediatos e visíveis - nesse campo, há coisas sutis que nem sempre vemos; 3) ter constância no trabalho - é melhor ler diariamente um poema com seus alunos do que realizar um "festival de poesia", nos lembra Drummond; e por último, é imprescindível que o professor seja um leitor de poesia.
\end{abstract}

Os trabalhos com a leitura de textos poéticos poderiam se tornar mais agradáveis se todos lessem e descobrissem quantas novidades podem estar guardadas nas palavras, nos versos ou nas entrelinhas das poesias. Segundo Candido (1996), "um texto poético não se revela por si mesmo", daí a necessidade de ler e compreender, saber ouvir, prestar atenção a todas as particularidades.

O leitor de textos poéticos tem que fazer a sua interpretação sem destruir o encanto a respeito da poesia e aprofundar, por meio do conhecimento, o prazer causado pela valia da obra. Em qualquer cultura a poesia pode denotar, definir ou apoiar-se sobre a lógica objetiva ou utilizar a conotação, a analogia e a metáfora para traduzir a sua subjetividade.

\title{
2 AS IMPLICAÇÕES PEDAGÓGICAS DO MODELO HISTÓRICO-CULTURAL
}

Ao buscar compreender processos educativos que contemplem uma aproximação do aluno com a poesia, procura-se na perspectiva da Psicologia Histórico-Cultural, proposta por Vygotsky (1991), uma sugestão com o aprendizado. O professor não deve se concentrar no Nível de Desenvolvimento Real (NDR), isto é, em certos ciclos de desenvolvimento já completados, amadurecidos, mas na Zona de Desenvolvimento Proximal ${ }^{5}$ (ZDP), que define aquelas funções que ainda estão em processo de amadurecimento.

Vygotsky (1991) propõe um processo de intervenção para promover a apropriação de certos conhecimentos, habilidades ou aptidões. Isso pode ocorrer mediante a interação e a cooperação com o outro. Esse processo prioriza o conhecimento dos alunos inter-relacionados

5 - Neste trabalho optou-se pelo uso do termo "Zona de Desenvolvimento Proximal" como sinônimo de Zona de Desenvolvimento Potencial ou Zona de Desenvolvimento Imediato. Nas diferentes traduções da obra de Vygotsky este termo apresenta-se com um ou outro nome. 
ao conteúdo de aprendizagem escolar e toma como ponto de partida os significados e os sentidos que os alunos dispõem em relação a esse conteúdo. Ao mesmo tempo, deve provocar desafios que os levem a questionar esses significados e sentidos, despertando vários processos internos de desenvolvimento.

O aprendizado humano pressupõe uma natureza social específica e um processo onde as vivências intelectuais das pessoas envolvidas interpenetram-se. Assim o professor passa a ser o mediador. Aquele que vai proporcionar outras abordagens para a compreensão da poesia.

Segundo Chalhub (1998),

o ato de leitura, antiqüíssimo, é relacional: do poeta ao leitor, persiste a sombra da linguagem de um e de outro, marcados que são pela expectativa do encontro. Diz o receptor: 'Que vou aí encontrar, neste algo pronto e dado?'. E viaja na travessia da descoberta de inúmeras significações que o texto oferece nos caminhos e tropeços do ato de leitura. Porque o encontro que aí se dá é o da linguagem: do poeta e do leitor, construtores de signos.

O pensamento de Vygotsky (1991) leva à reflexão sobre a importância da escola na atuação e transformação de seu meio social e de construção de novos conhecimentos. Isso acontece porque muitas vezes o professor é a única pessoa competente ou disponível para oferecer aos alunos leituras que vão ampliar esse universo infantil. Para isso deve-se reconhecer e intervir na Zona de Desenvolvimento Proximal, para que em determinada tarefa e em determinado momento o aluno possa acrescentar a sua aprendizagem novos conhecimentos.

Assim, o professor não deve apenas transmitir conteúdos, mas ensinar o aluno a pensar e apropriar-se do conhecimento elaborado, que servirá a ele tanto dentro da escola como também quando estiver fora dela, pois o longo caminho do desenvolvimento humano, nessa perspectiva teórica, segue do social para o individual.

A importância deste estudo é contribuir para que trabalhos sobre a literatura infantil, especialmente a poesia, tendo como referencial teórico o modelo histórico-cultural, possa auxiliar a construção do desenvolvimento real dos alunos; e no papel do professor mediador, que é aquele que vai proporcionar ao aluno novas leituras e novos conhecimentos.

\section{A IMPORTÂNCIA DA LEITURA LITERÁRIA NA ESCOLA}

O ensino de literatura, da $1^{\mathrm{a}}$ a $4^{\mathrm{a}}$ séries do Ensino Fundamental, de acordo com os Parâmetros Curriculares Nacionais (BRASIL, 1997), faz pensar sobre a literatura como: “Autonomia relativa ante o real (...), invenções de linguagem, a expressão das subjetividades, o trânsito das sensações (...) mecanismos ficcionais e racionalizantes".

$\mathrm{Na}$ escola é necessário que a literatura não seja usada como uma forma particular de escrita (BRASIL, 1997), 
Com isso, é possível afastar uma série de equívocos que costumam estar presentes na escola em relação aos textos literários, ou seja, tratá-los como expedientes para servir ao ensino das boas maneiras, dos hábitos de higiene, dos deveres do cidadão, dos tópicos gramaticais, das receitas desgastadas do "prazer do texto", etc.

Cabe então ao professor desenvolver estratégias que contribuam para a formação de alunos leitores capazes de reconhecer as particularidades, os sentidos, as sutilezas, a extensão e a profundidade de um texto literário. Assim, o papel da literatura nos primeiros anos pode ser considerado fundamental para que se processe no indivíduo uma relação ativa entre o leitor e o texto.

A escola, sendo um espaço privilegiado para trabalhar a leitura ou o único espaço que muitas crianças têm, deve ir à busca de novos projetos e valorizar a prática social do aluno e o seu conhecimento histórico. Dietzsch (1989) acredita que:

O ponto de partida seria a prática social do aluno e o de chegada, o conhecimento historicamente construído: um novo projeto de escola sendo buscado. Sem deixar de lado o afetivo e a fantasia infantil, procurar-se-ia o contato com um mundo inteligente, vivo, real, que se recria na literatura infantil, ou que se faz presente no texto do jornal e na discussão do que está acontecendo no Bairro, em São Paulo, ou no Golfo Pérsico $[\ldots]$

É preciso privilegiar a leitura de textos literários, pois "a literatura, muito mais que um objeto portador de mensagens e ensinamentos, é um jeito particular de enxergar o mundo" (PARANÁ, 1992).

A leitura é atividade cognitiva por excelência, sobre a qual se fundamenta todo o processo de desenvolvimento escolar. Deve estar fundamentada numa prática básica, a da leitura crítica, em que o trabalho do educador é viabilizar a formação do leitor, levando sempre em conta o contexto sócio-histórico do aluno, suas representações do mundo e permitir ou mediar a sua construção de sentidos.

Para que o leitor em formação se torne um aluno-leitor competente convém que o educador considere, utilize e ative o conhecimento que ele já tem; prediga as informações que ele irá encontrar no texto e estabeleça a finalidade da leitura.

Para Zilberman (1991),

\footnotetext{
A leitura se democratiza ao se tornar acessível a qualquer grupo indistintamente, esta inclinação só se fortalece se detonar uma perspectiva crítica e atuante, segundo a qual o leitor se singulariza, porque se posiciona não apenas diante do objeto livro colocado à sua frente, mas perante o mundo que ele traduz.
}

A escola é o lugar onde se aprende a ler, escrever, conhecer a literatura e desenvolver o gosto pela leitura. Porém, para a leitura ser um projeto de crescimento do aluno, ainda que às vezes limitado, é necessário que apareçam novas práticas mais estimulantes, que propiciem a transformação do aluno em aluno-leitor. 
A compreensão de um determinado texto ocorre quando há a integração entre textoleitor e constituição dos processos de significação.

A relação entre o sujeito-leitor e o texto precisa passar por mediações e por experiências de linguagem.

Lajolo (1995), diz que:

Cada leitor, na individualidade de sua vida, vai entrelaçando o significado pessoal de suas leituras com os vários significados que, ao longo da história de um texto, este foi acumulando. Cada leitor tem a história de suas leituras, cada texto, a história das suas.

A leitura infantil no contexto escolar representa um estímulo a novas aprendizagens e proporciona à criança a ampliação do universo cultural e criativo. Assim, a criança passa a ler melhor, escrever melhor, ter mais habilidade com as palavras e consequentemente ser mais crítico, no seu dia-a-dia, ter mais autonomia de criação e uma visão de mundo maior.

A sala de aula sendo um espaço privilegiado para o trabalho com a leitura, é necessário que a escola invista em bons livros, e o professor reconheça o valor dessa literatura e faça uso regular desses livros. Não só de histórias, fábulas, contos e outros, mas também de poesias, que é o que mais se aproxima das brincadeiras infantis.

Para Zilberman (1994), a escola deve:

Abordar as relações entre a literatura e o ensino, legitimando a função da leitura em virtude das motivações dos recebedores crianças e sugerindo livros, assim como atividades didáticas, a fim de alcançar o uso da obra literária em sala de aula com objetivos cognitivos, e não apenas pedagógicos.

Casasanta (1969) diz que, "a poesia deve ser apresentada para ser sentida. Para despertar e provocar emoção. Lida. Falada. Ouvida. A poesia deve ser sempre uma fonte de encantamento para a criança" (p.100). E que a escola deve dar ênfase ao trabalho com a poesia porque ela é para deleitar a criança; incutir-lhe o amor à beleza, desenvolver-lhe o gosto estético, o pensamento e a linguagem. Por tudo isso, a principal finalidade da poesia, na escola, segundo Casasanta (1969), “é despertar na criança a emoção poética” (p.101).

\section{O TRABALHO EMPÍRICO: PROCEDIMENTOS E RESULTADOS}

\subsection{CONTEXTUALIZAÇÃO}

O trabalho foi aplicado em uma sala de $4^{\mathrm{a}}$ série do Ensino Fundamental, em uma escola municipal, durante o período do estágio, no ano letivo de 2007. Essa classe é freqüentada por 24 crianças, sendo 15 do sexo feminino e 9 do sexo masculino. 
$\mathrm{Na}$ análise do desenvolvimento do trabalho foram utilizadas poesias de Cecília Meireles, Vinícius de Moraes e Henriqueta Lisboa, desenhos, comentários e poesias dos alunos e entrevista. Toda a sala participou. As Atividades aqui apresentadas foram selecionadas aleatoriamente para a análise.

\subsection{APRESENTAÇÃO DA POESIA À CLASSE}

A poesia A Casa, de Vinícius de Moraes é apresentada a todos os alunos da classe:

A CASA
Era uma casa
Muito engraçada
Não tinha teto
Não tinha nada
Ninguém podia
Entrar nela não
Porque na casa
Não tinha chão
Ninguém podia
Dormir na rede
Porque na casa
Não tinha parede
Ninguém podia
Fazer pipi
Porque penico
Não tinha ali
Mas era feita
Com muito esmero
Na Rua dos Bobos
Número Zero.

Vinícius de Moraes

A pesquisadora, com a autorização da professora da sala, leu a poesia para os alunos. Depois pediu para que alguns lessem. Todos quiseram ler e no final fizeram uma leitura em conjunto.

Os alunos leram com muito entusiasmo e demonstraram grande alegria em poder compartilhar esse momento. Logo depois, pediu-se a eles que ilustrassem a poesia, usassem toda a imaginação e a criatividade.

\subsection{AS ILUSTRAÇÕES}

Quanto às ilustrações, a pesquisadora deixou os alunos à vontade para cumprirem essa tarefa. O que se esperava era um diálogo criativo entre imagem e texto. Segundo Silva, Márcia, (2000), 
No poema, “A Casa”, há índices de uma brincadeira, com o sem sentido da construção da casa imaginária e do engano da rua dos bobos, número zero. O jogo é estabelecido, então, entre a expectativa de quem espera ver a ilustração de uma casa que "não tinha teto", "não tinha chão", "não tinha parede".

As ilustrações ${ }^{6}$ aqui apresentadas, sobre a poesiaACasa, de Vinícius de Moraes, escolhidas aleatoriamente, mostram que alguns alunos apresentam maior facilidade em compreender o tema da poesia, enquanto que outros têm mais dificuldade em relacionar o texto poético com o desenho. Alguns chegaram a perguntar para a professora se podiam deixar a folha em branco. Ela respondeu que eles deveriam decidir o que queriam fazer.
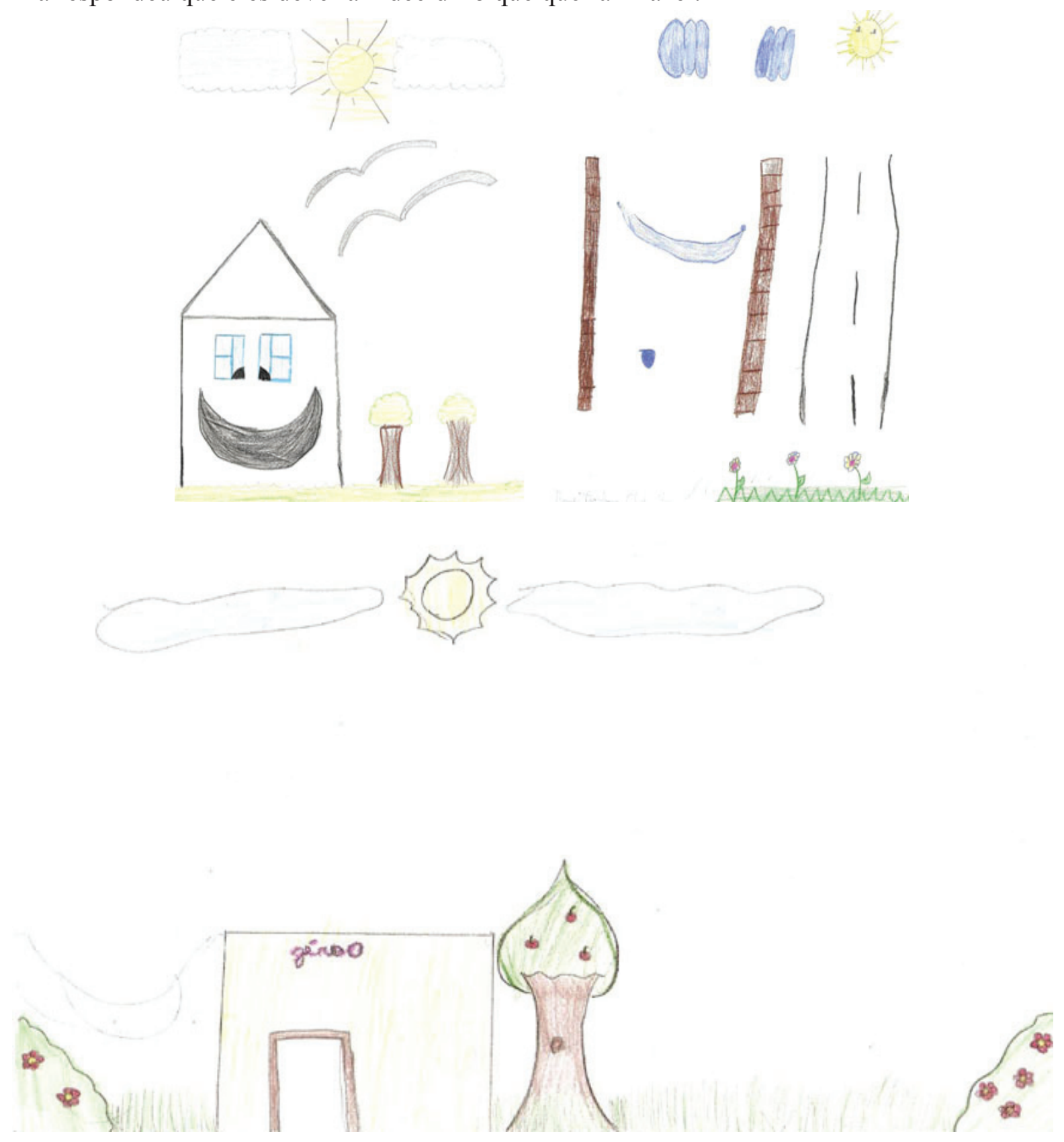

$6 \quad$ Optou-se por não identificar os alunos. 

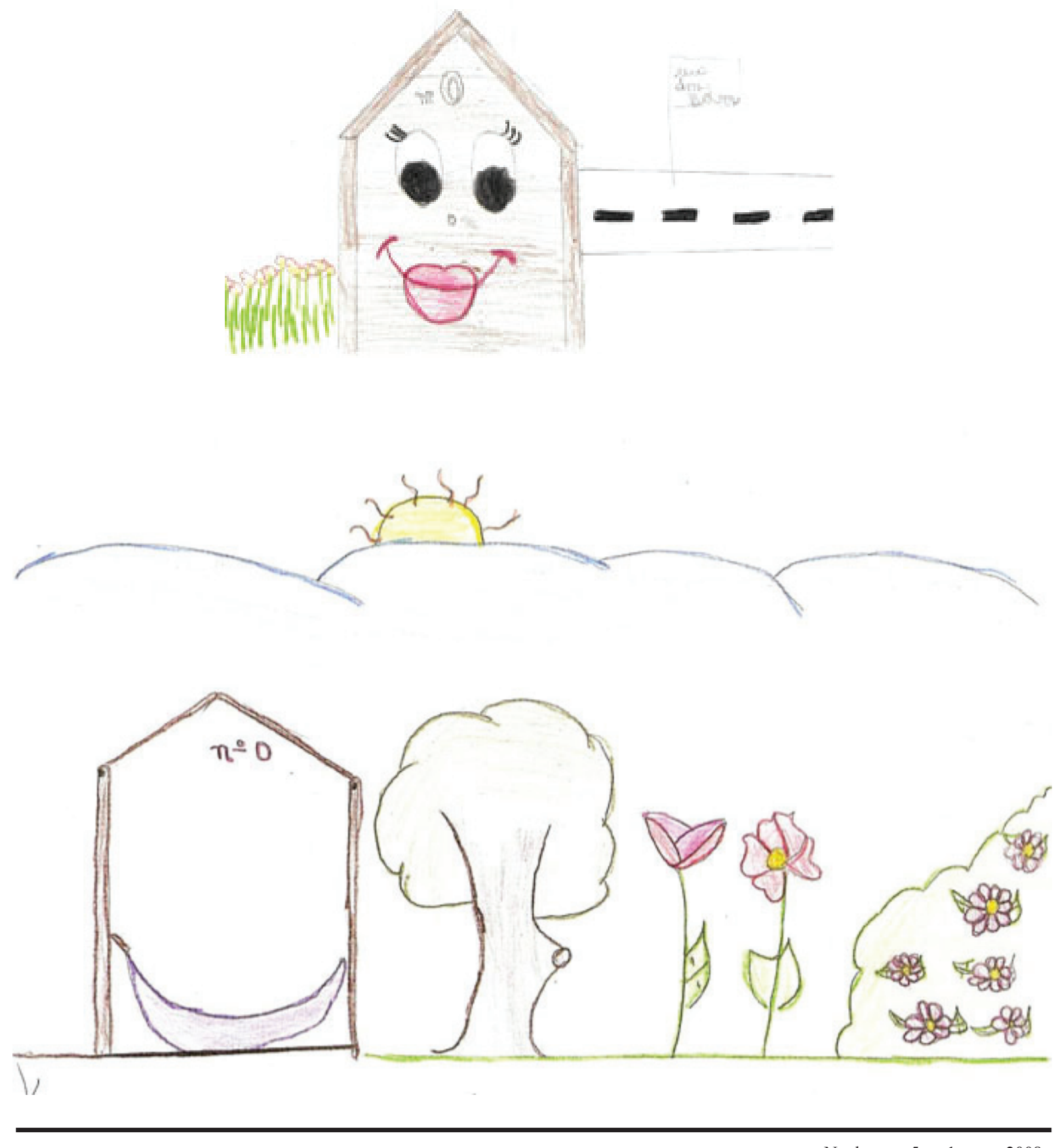

Nucleus, v. 5. n. 1 , mar. 2008 

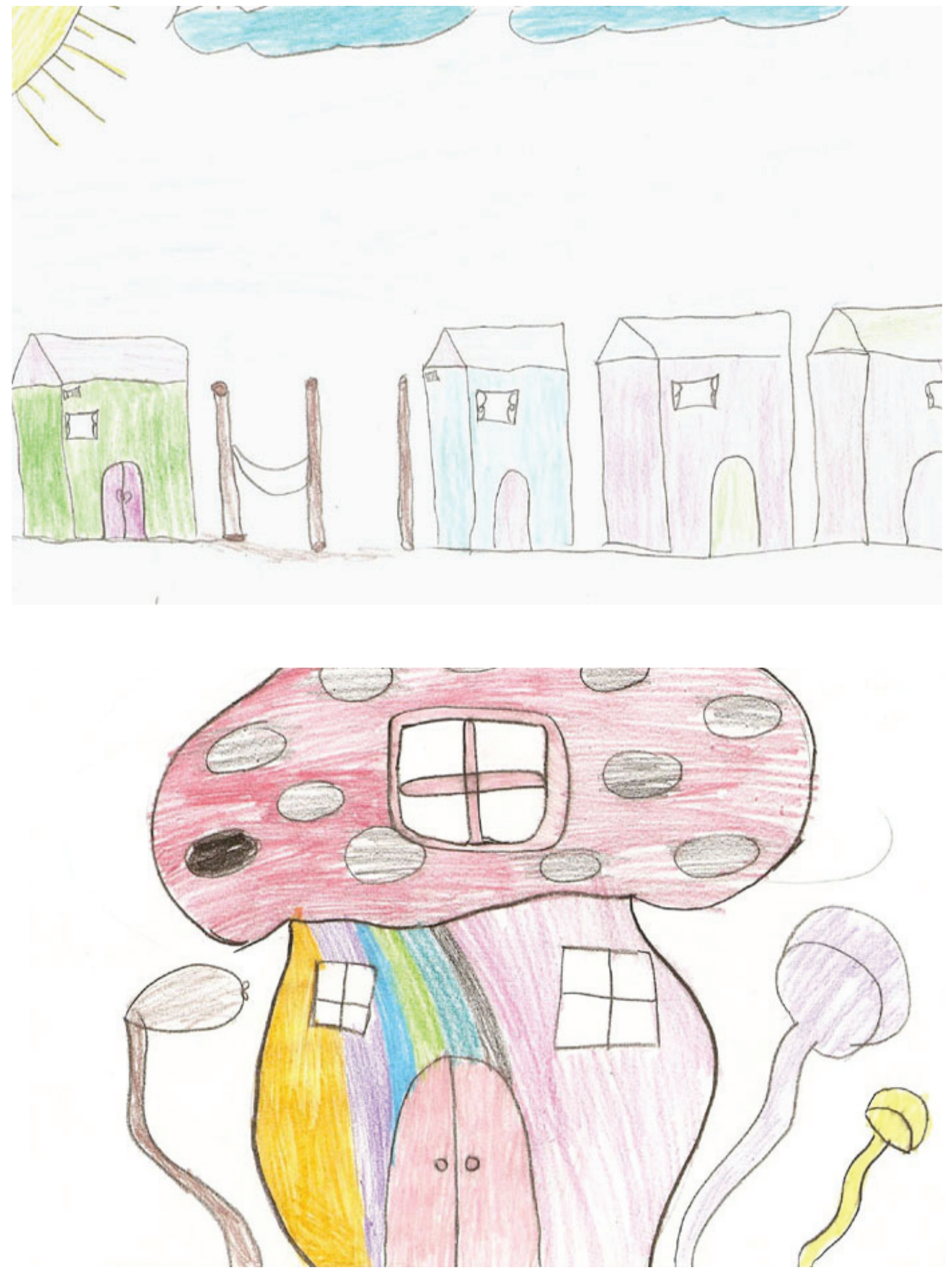

\subsection{O PAPEL DE MEDIADOR DO PROFESSOR}

A questão de mediação do professor é uma constante quando se quer analisar as relações entre aprendizagem e desenvolvimento. Assim, o conceito de Zona de desenvolvimento proximal, de Vygotsky (1991), é a diferença entre aquilo que a criança consegue realizar sozinha e aquilo que ela só consegue realizar sob a orientação de uma pessoa mais experiente, ou em colaboração com outras crianças. 
Quando a criança consegue realizar algo sozinha, Vygotsky (1991) chamou de nível de desenvolvimento real; quando ela precisa do outro para conseguir realizar algo, de nível de desenvolvimento potencial e a distância entre um nível e o outro de Zona de desenvolvimento proximal.

Assim, é na Zona de desenvolvimento proximal que entra o papel do professor mediador. É quando ele assume a intervenção nas situações interativas com as crianças (alunos). O professor nesse momento deve procurar ver as dificuldades das crianças e oferecer estratégias diversificadas para conseguir atingir assim o seu objetivo, ou seja, levar o aluno a atingir o seu Nível de desenvolvimento real.

Ao fazer uso desse pensamento de Vygotsky (1991), sob a intervenção do professor, criam-se algumas situações para que a criança se desenvolva de maneira qualitativa, e conscientemente ao realizar as atividades. Sendo assim, foram criados alguns momentos na realização das atividades com a leitura e compreensão de poesia.

\subsubsection{PRIMEIRO MOMENTO}

Diante de algumas dificuldades apresentadas pelos alunos, a pesquisadora, que neste momento estava como a professora da sala, propôs a todos que sentassem em círculo, inclusive ela também.

Pediu-se aos alunos que um de cada vez, no sentido horário, comentasse sobre a poesia. Nesse momento o objetivo era perceber as dúvidas e a falta de entendimento que eles apresentavam.

Após todos terem se manifestado e até compartilhado as suas idéias com o grupo, a atividade se encerrou e ficou marcado um próximo encontro entre a pesquisadora e os alunos.

\subsubsection{SEGUNDO MOMENTO}

Chegou o outro dia, as crianças receberam a "nova professora", é como eles passaram a chamar a pesquisadora, com muito entusiasmo e alegria. Ela levou várias poesias, impressas em folhas de papel, outras estavam nos livros, de autores diferentes e também com temas diferentes, como: amor, amizade, sonho, flor, natureza, brincadeira, etc. para serem lidas pelos alunos.

Realizou-se uma leitura silenciosa para conhecimento dos textos, aqui, não se observou qualquer resposta do contato com os poemas. Havia um silêncio geral na classe. Seguiu-se a leitura em voz alta pela pesquisadora e depois alguns alunos leram as poesias que estavam com eles. A pesquisadora pediu aos alunos que falassem dos textos. Esse momento foi muito proveitoso e de muita descontração.

Cada criança escolheu um tema que gostasse, não precisava ser das poesias que foram 
lidas, e escrevesse um poema ou desenhasse. Os alunos deveriam usar nesse momento toda a sua criatividade, expressar seus sentimentos, a sua imaginação, criar, recriar, fazer uma poesia.

Apesar de o tema ser livre, pode-se perceber que vários alunos optaram por aqueles que haviam sido trabalhados naquela semana em outras disciplinas como: o trânsito, o respeito, a seca, etc. Mesmo assim, o resultado foi surpreendente, pois o contato com a poesia permitiu que eles colocassem a sua espontaneidade, as suas emoções de forma prazerosa.

Apresentamos aqui algumas poesias e ilustrações ${ }^{7}$ feitas pelos alunos:
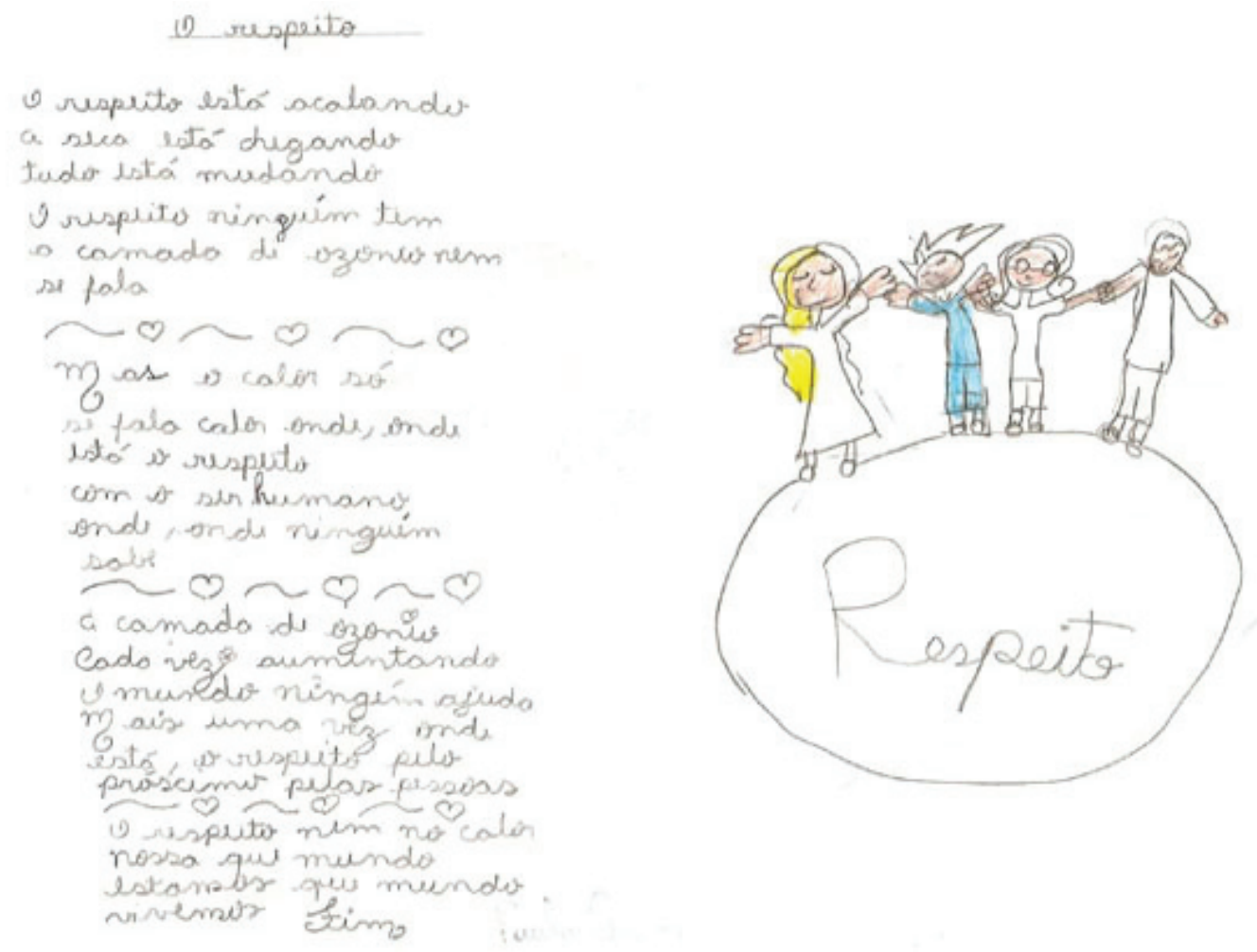

$7 \quad$ As poesias e ilustrações foram escolhidas aleatoriamente pela pesquisadora. 
Sertáo

no sentao

í bom mona

Poir lá gosto

de ficon

$\sim 11$

tem vários winas

logais

Pisn lá im

omimals.

hes $\operatorname{sen} \overline{T_{0}}$

i'molar quente

Vamos monas

lá un a gento

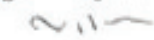

20 jou um fim

nesso estrúa

\& háe verto sem

dar um fora.

\section{FIM.}

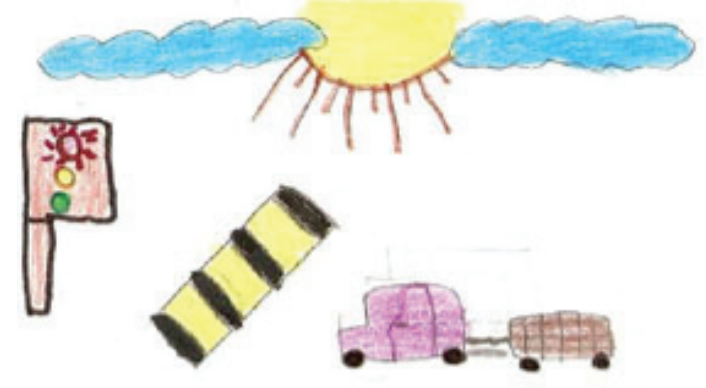

Quando \& Sinal estrues Pechado, mesmo se nas estiver pedostes arra- ressando esperer poes. Q Prigo está perta de nós.

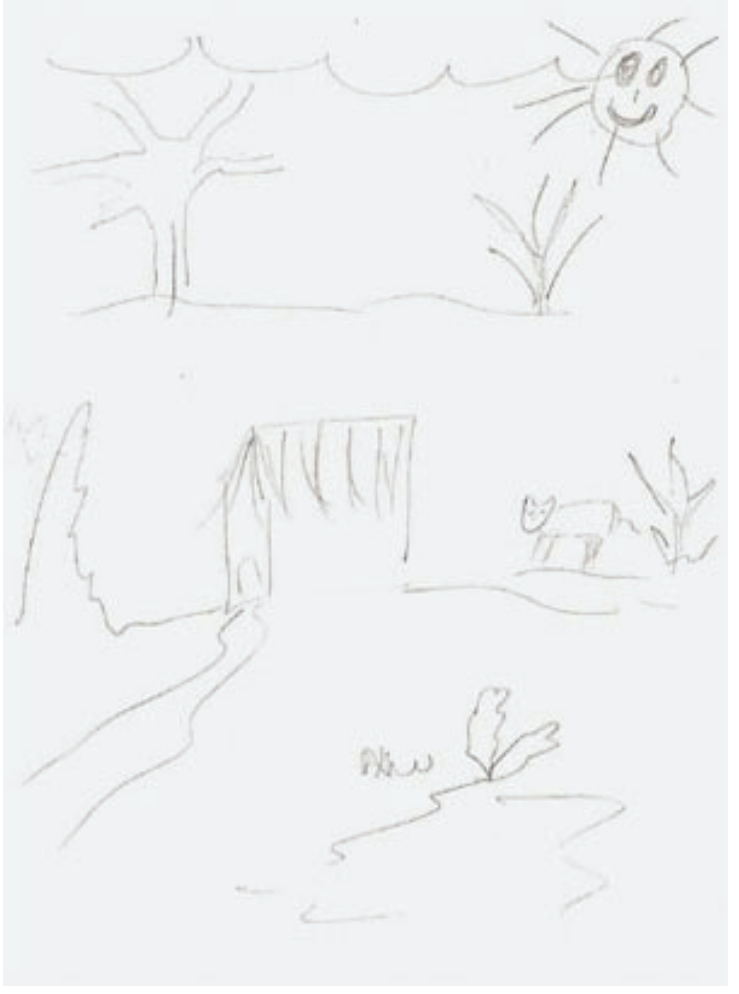

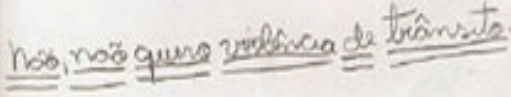

9 tiansista é lom,

Sö́r bom, quanto nosa. Vrda.

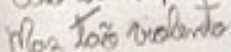

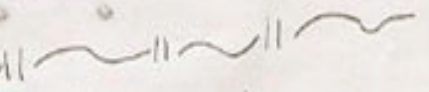

Pevránas paran con tudó de ruvimi sim.

Pevránas paran con tudó de ruvimi sim.

Se as perseas ajudassem,

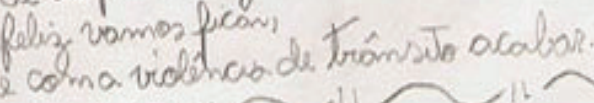

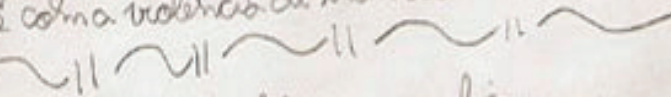

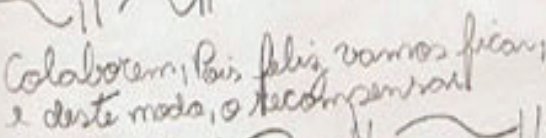

حil $\sim 112$ त $i \wedge 1$ 

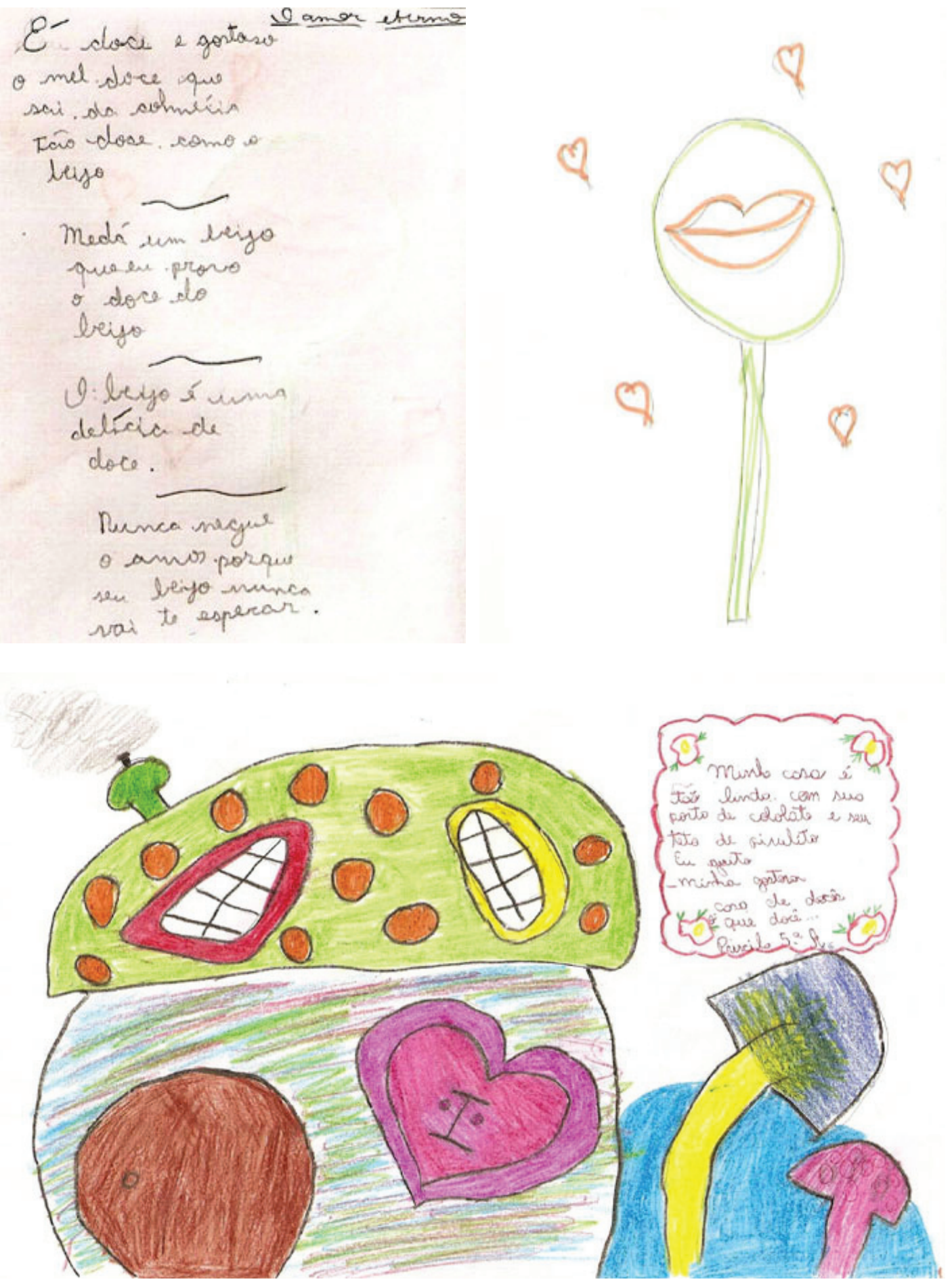

\subsubsection{A ENTREVISTA}

Passado uma semana a pesquisadora voltou à escola, na mesma sala de aula, e fez uma entrevista com os vinte e quatro alunos, da classe, em forma de perguntas e respostas. Cada criança, silenciosamente, respondeu às questões, que perguntavam:

$1^{\mathrm{a}}$ : Você gosta de poesias? Por quê?

Respondeu que sim vinte e três alunos, apenas um não gostava de poesia. Os que 
responderam que sim, usaram como justificativas respostas como: gosto de poesias porque são legais, engraçadas, emocionantes, românticas e também porque algumas são divertidas, lembram coisas boas. Outros disseram que é porque gostam de ler.

\section{$2^{\text {a }}$ : Você lembra de alguma poesia que leu e gostou muito? Qual?}

Das vinte e quatro crianças, quatro responderam não lembrar, oito gostavam da poesia A Casa, trabalhada na sala de aula, e os outros citaram poesias que leram durante esse projeto, como: O relógio, Namorinho no portão, A foca fugitiva, Bem te vi, Bolhas, etc.

\section{$3^{\text {a }}$ : Que tipo de poesia você não gosta? Ou você gosta de todas?}

Vinte crianças responderam gostar de todas as poesias e três disseram que não gostavam de poesias, nem emocionantes, nem românticas e nem que falavam de tristeza. Uma criança não respondeu nada.

\section{$4^{\text {a }}$. Você lê poesias só na escola ou fora da escola também?}

Vinte e uma crianças responderam que lêem poesias fora da escola também. Três responderam que não lêem fora da escola.

\section{$5^{\text {a }}$. Na sala de aula vocês costumam ler muitas poesias ou poucas?}

Vinte crianças responderam ler poucas poesias dentro da sala de aula, um respondeu que não costuma ler poesia e três responderam ler muitas poesias.

\section{$6^{\text {a }}$. Em casa a mamãe e o papai lêem poesias ou algum tipo de histórias para você.}

Doze crianças responderam que a mamãe e o papai não lêem poesia e nem outro tipo de texto ou história. Um respondeu que lê sozinho, dois responderam que leem de vez em quando e nove responderam que a mamãe e o papai lêem poesias para eles e também histórias de crianças.

$7^{\text {a }}$. Você gostou da poesia de hoje? Ela te fez lembrar de alguma coisa boa que você já viveu?

As vinte e quatro crianças responderam que gostaram muito da poesia "A casa". Dezoito crianças disseram que a poesia fez lembrar momentos engraçados e de como a casa poderia ser.

Sendo assim, das vinte e quatro crianças entrevistadas na sala, apenas uma nos relatou não gostar de poesias. A maioria gostou e achou muito divertido. Através da entrevista ficou claro que a leitura de poesias na sala de aula, pode ser um instrumento para auxiliar o desenvolvimento cultural e criativo da criança.

\section{CONSIDERAÇÕES FINAIS}

Neste trabalho procurou-se demonstrar como a literatura infantil, neste caso, a poesia pode ser um instrumento pedagógico extremamente relevante durante todo o período de alfabetização, que se transforma num processo que vai além do desenvolvimento das habilidades de codificação e decodificação. 
Isso abrange também o estímulo a um estilo de linguagem que pode ser extremamente importante para o desenvolvimento escolar da criança. Segundo Cunha (1985),

As pesquisas mostram uma tendência natural da criança para a poesia (...) O mundo infantil é cheio de imagens, como o campo da poesia. A fantasia e a sensibilidade caracterizam ambos. O predomínio da linguagem afetiva existe na poesia e na criança.

O professor da classe é a pessoa mais indicada para escolher e trabalhar com poesias, pois é importante que ele se sensibilize, emocione, familiarize com o poema para depois apresentálo aos alunos. E nunca esperar que os alunos reajam sempre positivamente a um mesmo poema, pois o que agrada a um não precisa necessariamente agradar a todos.

De todos os gêneros, a poesia deve ser o menos comprometido, com apresentações, declamações e aspectos morais, pois é mais importante que o aluno sinta a poesia do que a compreenda.

Cunha (1985), diz que é:

Muito agradável ao aluno e verdadeiramente educativo é partir-se do poema para novas formas de expressão. Sob a sugestão do texto, os desenhos, as montagens, o coro falado, a tentativa de criação de novos poemas, são meios de desenvolver a criatividade das crianças. Temos visto trabalhos de alunos bem pequenos, e as surpresas são sempre agradáveis nesse campo. Afinal, todas as estratégias capazes de aguçar a sensibilidade da criança e do adolescente para a poesia são válidas. Parecenos importante ressaltar, entretanto, que para essa sensibilização é fundamental a freqüência com que a poesia lhes é apresentada.

Através da entrevista respondida pelos alunos, percebe-se que a ausência do trabalho com a poesia, ou a pouca freqüência que ela é levada aos alunos, na sala de aula, representa uma falta de estímulo e incentivo à leitura desse gênero.

Para um bom aprendizado a criança precisa conviver com modelos diversificados de textos. E a poesia além de proporcionar prazer ela vai intensificar o lúdico, o sentimento e a imaginação. Assim, ela pode ser uma alternativa a mais para desenvolver o gosto pela leitura.

Os educadores devem buscar cada vez mais aprimorarem a sua competência leitora, através de outros colegas, em livros que relatam experiências, em oportunidades de novas aprendizagens, em participações em cursos, estudos, etc., pois são eles os mediadores mais próximos dos alunos. São eles que vão intervir (VYGOTSKY, 1991) na Zona de desenvolvimento proximal do aluno e transformá-la em Zona de desenvolvimento real.

Assim, consideramos que trabalhar com a poesia é proporcionar aos nossos alunos uma ampliação do seu universo cultural e criativo, que terá como conseqüência uma aprendizagem mais dinâmica e satisfatória para que os alunos se transformem em alunos-leitores.

"Seja de uma forma ou de outra, a poesia segue seu caminho, deixando em nós de tudo um pouco, mesmo que só por um instante - o instante da sala de aula." (SILVA, Maria, 2000, p. 101-102). 


\section{REFERÊNCIAS}

ABRAMOVICH, F. Literatura infantil: gostosuras e bobices. 5. ed. São Paulo: Scipione, 2001.

ANDRADE, C. D. de. Antologia poética. 48 ed. São Paulo: Record, 2001.

. Literatura infantil. In: Confissões de Minas. Rio de Janeiro: Aguilar, 1964.

ANDRÉ, M.E.D. A pesquisa no cotidiano escolar. In: FAZENDA, I. (org.). Metodologia da pesquisa educacional. 2. ed. aument. São Paulo: Cortez, 1991.

BANDEIRA, M. Antologia poética. 17. ed. Rio de Janeiro: J. Olympio, 1986 p. 170.

BRASIL. Ministério da Educação, Secretaria de Educação Média e Tecnológica. Parâmetros curriculares nacionais: ensino fundamental. Brasília: Ministério da Educação, 1997.

CÂNDIDO, A. Estímulos da criação literária. In: Literatura e sociedade: estudos de teoria e história literária. 3 ed. são Paulo: Nacional, 1973.

USP, 1996.

. O estudo analítico do poema. 3. ed. São Paulo: Humanitas Publicações - FLCH/

CASASANTA, T. Criança e literatura. 3. ed. Belo Horizonte: A Grafiquinha, 1969.

CHALHUB, S. A metalinguagem. 4. ed. São Paulo: Ática, 1998.

COELHO, N. N. Literatura infantil: teoria, análise, didática. São Paulo: Moderna, 2000.

CUNHA, M. A. A. Literatura infantil: teoria e prática. 3. ed. São Paulo: Ática, 1985.

DIETZSCH, M. J. M. Escrita: na história, na vida, na escola. (Cadernos de Pesquisa, 71), p.6271, nov.1989.

FERREIRA, A. B. de H. Dicionário Aurélio básico da língua portuguesa. Rio de Janeiro: Nova Fronteira/Folha de São Paulo, 1995.

LAJOLO, M. Do mundo da leitura para a leitura do mundo. São Paulo: Ática, 1995.

LISBOA, H. O menino poeta. Rio de Janeiro: Bedeschi, 1943.

LUFT, C. P. Minidicionário Luft. 12. ed. São Paulo: Ática, 1996. 
LYRA, P. Conceito de poesia. São Paulo: Ática, 1986. (Série Princípios).

MEIRELES, C. Isto ou aquilo. 3. ed. Rio de Janeiro: Civilização Brasileira, 1979.

OLIVEIRA, M. K. de. O pensamento de Vygotsky como fonte de reflexão sobre educação. Campinas, p. 11-18, jul. 2000. (Cadernos Cedes, n. 35).

PAES, J. P. Poesia para crianças: um depoimento. São Paulo: Giordano, 1996. p. 24-25.

PALO, M. J.; OLIVEIRA, M. R. D. Literatura infantil: voz de criança. São Paulo: Ática, 1986.

PARANÁ. Secretaria da Educação. Superintendência de Educação. Departamento de Ensino de Primeiro Grau. Currículo básico para a escola pública do Paraná. Curitiba, 1992.

PINHEIRO, H. Poemas para crianças e jovens. In: PINHEIRO, H. (org.). Poemas para crianças: reflexões, experiências, sugestões. São Paulo: Duas Cidades, 2000. p. 11-32. (Coleção Literatura e Ensino, 1).

RICARDO, Cassiano. Seleta em prosa e verso. 2. ed. Rio de Janeiro: J. Olympio, 1975. p.60.

SMOLKA, A. L. B. A criança na fase inicial da escrita: a alfabetização como processo discursivo. São Paulo; Campinas: Cortez/Ed. da Unicamp, 1988.

SILVA, Márcia T. Brincar com palavras e imagens. In: PINHEIRO, H. (org.). Poemas para crianças: reflexões, experiências, sugestões. São Paulo: Duas Cidades, 2000. p. 143-163. (Coleção Literatura e Ensino, n.1).

SILVA, Maria C. R. da. De poesia, experiências e descobertas. In: PINHEIRO, H. (org.). Poemas para crianças: reflexões, experiências, sugestões. São Paulo: Duas Cidades, 2000. p. 101-122. (Coleção Literatura e Ensino, n. 1).

SOSA, J. A literatura infantil. 9. ed. Tradução de James Amado. São Paulo: Cultrix, 1993.

VYGOTSKY, L. S. A Formação social da mente. São Paulo: Martins Fontes, 1991. . Psicologia pedagógica. São Paulo: Martins Fontes, 2001.

ZILBERMAN, R. A Leitura e o ensino de literatura. 2 ed. São Paulo: Contexto, 1991. . A Literatura infantil na escola. 8 ed. São Paulo: Global, 1994. 